\title{
Early Appearance and Spread of Fast Ripples in the Hippocampus in a Model of Cortical Traumatic Brain Injury
}

\author{
Franco Ortiz, ${ }^{1,2}$ W.P. Karel Zapfe, ${ }^{1}{ }^{\circledR}$ Andreas Draguhn, ${ }^{3}$ and ${ }^{\circledR}$ Rafael Gutiérrez ${ }^{1,3}$ \\ ${ }^{1}$ Departamento de Farmacobiología del Centro de Investigación y de Estudios Avanzados del IPN México City, 14330, ${ }^{2}$ Instituto de Fisiología Celular, \\ Universidad Nacional Autónoma de México, México City 04510, México, and 3 Institut für Physiologie und Pathophysiologie, University of Heidelberg, \\ 69120 Heidelberg, Germany
}

Fast ripples (FRs; activity of $>250 \mathrm{~Hz}$ ) have been considered as a biomarker of epileptic activity in the hippocampus and entorhinal cortex; it is thought that they signal the focus of seizure generation. Similar high-frequency network activity has been produced in vitro by changing extracellular medium composition, by using pro-epileptic substances, or by electrical stimulation. Here we study the propagation of these events between different subregions of the male rat hippocampus in a recently introduced experimental model of FRs in entorhinal cortex-hippocampal slices in vitro. By using a matrix of 4096 microelectrodes, the sites of initiation, propagation pathways, and spatiotemporal characteristics of activity patterns could be studied with unprecedented high resolution. To this end, we developed an analytic tool based on bidimensional current source density estimation, which delimits sinks and sources with a high precision and evaluates their trajectories using the concept of center of mass. With this methodology, we found that FRs can arise almost simultaneously at noncontiguous sites in the CA3-to-CA1 direction, underlying the spatial heterogeneity of epileptogenic foci, while continuous somatodendritic waves of activity develop. An unexpected, yet important propagation route is the propagation of activity from CA3 into the hilus and dentate gyrus. This pathway may cause reverberating activation of both regions, supporting sustained pathological network events and altered information processing in hippocampal networks.

Key words: ca3; dentate gyrus; epilepsy; fast ripples; hippocampus; traumatic brain injury

\section{Significance Statement}

Fast ripples (FRs) have been considered as a biomarker of epileptic activity and may signal the focus of seizure generation. In a model of traumatic brain injury in the rat, FRs appear in the hippocampus within a couple of hours after an extrahippocampal, cortical lesion. We analyzed the origin and dynamics of the FRs in the hippocampus using massive electrophysiological recordings, allowing an unprecedented high spatiotemporal resolution. We show that FRs originate in distinct and noncontiguous locations within the CA3 region and uncover, with high precision, the extent and dynamics of their current density. This activity propagates toward CA1 but also backpropagates to the hilus and the dentate gyrus, suggesting activation of defined microcircuits that can sustain recurrent excitation.

\section{Introduction}

It has been proposed that very high-frequency oscillations or fast ripples (FRs; $>250 \mathrm{~Hz}$ ) signal the focus of seizure generation

\footnotetext{
Received Dec. 12, 2017; revised Aug. 3, 2018; accepted Aug. 8, 2018.

Author contributions: R.G. designed research; F.O. and W.P.K.Z. performed research; A.D. contributed unpublished reagents/analytic tools; F.O. and R.G. analyzed data; F.O., A.D., and R.G. wrote the paper.

This work was supported by Grants 79408 and 10110/193/10 FIB.UBST.-29-1010 from the Consejo Nacional de Ciencia y Tecnología (CONACYT), Mexico, Fundación Miguel Alemán and IBM to R.G. and by Grant SFB 1134 from the Deutsche Forschungsgemeinschaft to A.D. and R.G. W.P.K.Z. and F.O. were recipients of a postdoctoral and a doctoral fellowship from CONACYT, respectively. The data in this work are in partial fulfillment of the requirements for the doctoral degree of F.0. in "Programa de Doctorado en Ciencias Biomédicas," Universidad Nacional Autónoma de México. We thank Dr. Elías Manjarrez for introducing us to the concept of center of mass and Prof. Oscar Herreras for invaluable feedback on the current source density analysis.

The authors declare no competing financial interests.

Correspondence should be addressed to Rafael Gutiérrez at the above address. E-mail: rafagut@cinvestav.mx.
}

(Bragin et al., 1999). Experimentally, these activity patterns have been produced by high-frequency stimulation of the perforant path or the CA3 area, by rising $\mathrm{K}^{+}$concentration of the extracellular fluid, or by application of pro-epileptic compounds (for review, see Jefferys et al., 2012). We recently described an experimental model of FRs in rat entorhinal cortex-hippocampal slices in vitro that does not require additional manipulation in the recording conditions. This model requires a lesion in the entorhinal cortex in situ, before removal of the brain, which disrupts corticocortical and cortico-hippocampal connections producing an activity-dependent functional disinhibition of the hippocam- 
pus. This results in typical FRs in subsequently recorded brain slices (Ortiz and Gutiérrez, 2015).

It is already known that high-frequency activity arises in CA3 from where it propagates to downstream regions of the hippocampal formation (de la Prida et al., 2006; Both et al., 2008). Despite the wealth of anatomical descriptions of the hippocampal circuitry, propagation of activity between different subregions still challenges the current understanding of the network, leaving a plethora of potential pathways and mechanisms by which the hippocampus performs its functions. In particular, possible activation of anatomically restricted neuronal ensembles along the circuitry needs to be better understood. One possibly important propagation path is from CA3 to the dentate gyrus (DG). This would enable backpropagation of activity (Penttonen et al., 1997) and, therefore, recurrent activation of ensembles in both regions. Indeed, there are connections between CA3, the hilus, and DG (Myers and Scharfman, 2011), including electrical synapses (Vivar et al., 2012). Functional proof of propagating network activity at high spatiotemporal resolution along these pathways is, however, lacking.

To explore this possibility, we used a recently developed highdensity microelectrode array (MEA) with 4096 microelectrodes in a $64 \times 64$ matrix. This device allows recording of electrical activity at the network and single-unit level with unprecedented temporal and spatial resolution (Ferrea et al., 2012).

We demonstrate that it is possible to record FRs from entorhinal cortex-hippocampal slices under submerged conditions, originated by extra-hippocampal, entorhinal cortex lesions. We show that this activity appears predominantly in localized areas of the hippocampal CA3 region and often simultaneously in different locations. With newly developed analytical tools, we determine the dynamics of current density disjoint components during this activity, which propagate toward CA1 but also backpropagate to the DG. Interestingly, FRs can arise almost simultaneously at noncontiguous sites while somatodendritic activity current waves evolve. Thus, we uncover how current spreads in neuronal subsets with unprecedented high spatiotemporal resolution. Together, our data reveal that FRs arise in the hippocampus as early as $1 \mathrm{~h}$ after cortical trauma, suggesting that an epileptogenic focus may be building up long before seizure activity appears. Indeed, nonconventional pathways for the propagation of pathological network oscillations that underline the spatial heterogeneity of epileptogenic foci arise, which might set the limits to spatially confined therapeutic approaches.

\section{Materials and Methods}

Lesioning procedure and slice preparation. Experiments were performed on 25- to 30-d-old male Wistar rats. The Ethics Committee for Animal Research of our institution approved all experimental procedures, which were performed in adherence to the NIH Guide for the Care and Use of Laboratory Animals (eighth edition, 2011). We used a recently described model of traumatic brain injury that consists of making a horizontal cut in the entorhinal cortex in situ, before removing the brain for slice preparation. This protocol induces hippocampal disinhibition with the appearance of FRs in subsequently prepared transversal brain slices in vitro (Ortiz and Gutiérrez, 2015). We chose to prepare the slices with this orientation because it is well established that it preserves a high connectivity of the hippocampal subregions, especially DG to CA3 and CA3 to CA1 (Bischofberger et al., 2006; Boccara et al., 2015; Xiong et al., 2017), and because the lesion is also in the horizontal plane (Ortiz and Gutiérrez, 2015).

Briefly, rats were anesthetized with pentobarbital (50 mg/kg, i.p.). After rapid removal of the skull, cuts to the entorhinal cortex on each hemisphere, while the brain was still embedded in the skull, were per- formed with microsurgery scissors at the following coordinates (Paxinos and Watson, 1997): AP, from -5.3 to -6.8 (from bregma); lateral, from the middle of the brain $6-7$; depth, between 4 and 6 . The brain was removed after 5 min of continuous application of chilled ACSF in situ and submerged in oxygenated ACSF containing (in mM) $124 \mathrm{NaCl}, 3$ $\mathrm{KCl}, 1.25 \mathrm{NaH}_{2} \mathrm{PO}_{4}, 2 \mathrm{MgSO}_{4}, 2 \mathrm{CaCl}_{2}, 26 \mathrm{NaHCO}_{3}$, and 10 glucose, $\mathrm{pH}$ 7.35 , at $4^{\circ} \mathrm{C}$. We next prepared combined entorhinal cortex-hippocampal transversal slices (350 $\mu \mathrm{m}$; Vibroslicer, Leica VT1200).

Slices were incubated in oxygenated ACSF at room temperature at least $1 \mathrm{~h}$ before recordings commenced. We previously showed that this manipulation results in FRs, whereas slices incubated in a low-Ca ${ }^{2+}$, high- $\mathrm{Mg}^{2+}$ solution do not generate FRs (Ortiz and Gutiérrez, 2015). For recording, the slices were placed over a high-density MEA of 4096 electrodes (electrode size, $21 \times 21 \mu \mathrm{m}$; pitch, $42 \mu \mathrm{m}$; $64 \times 64$ matrix; 3 Brain). We placed a custom-made, square-shaped, platinum net anchor on top of the slices to avoid displacement by the ACSF flux and to ensure an even contact of the slices with the underlying chip containing the MEA. Slices were constantly perfused at $12 \mathrm{ml} \cdot \min ^{-1}$ with oxygenated, standard ACSF at $34 \pm 0.5^{\circ} \mathrm{C}$, and extracellular activity was digitized at 7 $\mathrm{kHz}$. For some recordings, we used a low- $\mathrm{Ca}^{2+} \mathrm{ACSF}$ solution containing the following (in mM): $125 \mathrm{NaCl}, 5 \mathrm{KCl}, 1.25 \mathrm{NaH}_{2} \mathrm{PO}_{4}, 0.2 \mathrm{CaCl}_{2}, 1$ $\mathrm{MgCl}_{2}, 26 \mathrm{NaHCO}_{3}$, and 10 glucose.

Data analysis. Recordings were acquired on a PC with the program Brain Wave in 5 min time windows (3Brain) and stored for off-line analysis. They were next analyzed with custom programs written either in Matlab (The Mathworks) or in Julia (Bezanson et al., 2017). For CA3 fast ripple detection, we isolated events with high amplitude using a criterion of 2 SD above the mean SD of baseline in consecutive $50 \mathrm{~ms}$ sweeps. A histogram with the distribution of SDs was constructed for each time window, and we could, therefore, sort out electrodes without activity or with saturating signals. A threshold was set for each of the active electrodes, excluding saturated ones. After automatic detection, we manually selected the electrodes that corresponded to the different regions of the hippocampus, hilus, and DG and checked for anatomical correspondence with photographs of the slices on the matrix, taken through a stereoscopic microscope.

Signals from active electrodes were bandpass filtered between 250 and $600 \mathrm{~Hz}$ using a fifth-order Butterworth filter and then rectified. A 5 SD threshold was used to detect high-amplitude peaks with at least three cycles of oscillations (i.e., six peaks). Linear trends were removed from their cumulative sum to identify abrupt changes in the slope of the signal indicating the initiation and termination of the event. Because FRs have a mean incidence of $0.4 \mathrm{~Hz}$ and a duration of $\sim 50 \mathrm{~ms}$ (Dzhala and Staley, 2003; Foffani et al., 2007), we stored raw and filtered samples starting 100 $\mathrm{ms}$ before the first peak until $200 \mathrm{~ms}$ after the last peak of each detected event for further analysis. We next calculated power spectra for each raw event to confirm its classification as a FR, in which case it should present a peak frequency between 250 and $600 \mathrm{~Hz}$.

Experimental design and statistical analyses. We used a within experimental design in which all brains were subjected to the entorhinal cortex bilateral lesion in situ. We used a total of nine slices from seven different animals and a maximum of two slices per animal. We switched the normal ACSF to a solution with low calcium in three of the slices that showed FRs and waited $40 \mathrm{~min}$ for the calcium to wash out before recording any activity.

Four parameters were used to describe FRs: incidence, amplitude, duration, and frequency oscillation. Each parameter measured was taken from each electrode that recorded a FR event. Because this parameter followed a log-normal distribution, we report the geometric mean and multiplicative and divisive errors.

For the Granger causality test, a significance level for each pair of signals of all the signals recorded per FR event was determined, whereby we report a significance level of $p \leq 0.05$ (see below, Granger causality test). The programs for analyses were written in Matlab, except for the current source density analysis (CSDA) that was written in Julia (available upon request).

Granger causality test. The use of the Granger causality test has been deemed suitable to study neuronal connections (Gaillard et al., 2009). Given two time series, $X_{1}$ and $X_{2}$, this test determines whether one series 
influences the other. In brief, $X_{2}$ Granger causes $X_{1}$ if the inclusion of past values of $X_{2}$ reduces the prediction error of $X_{1}$ in a linear regression model of $X_{1}$ and $X_{2}$ compared with a model that includes only past values of $X_{1}$ (Granger, 1969). For our recordings with the high-density matrix, once we selected the electrodes that recorded a relevant event, we took a sample of $300 \mathrm{~ms}$ containing the event. Granger causality interactions were computed between all possible pairs of electrodes with a conditional multiple regression model. The script was written in Matlab and is part of an open library (Barnett and Seth, 2014). We determined the interactions between electrodes in the DG and CA3 and between electrodes in the CA3 and CA1.

Current source density analysis. We conducted bidimensional CSDA as follows. In the first step, we discarded unusable (e.g., saturated) channels. We detected saturated channels when the recorded signal had less variance than the noise levels. In such a case, the saturated signal was replaced with the average of its eight neighboring electrodes. After this, a Gaussian smoothing filter with a half-width of $42 \mu \mathrm{m}$ was applied to reduce the effect of hard edges on the data. We then conducted the CSDA using convolution with the following operator:

$$
\nabla_{L}^{2}=2 / 3\left(\begin{array}{ccc}
0 & 1 & 0 \\
1 & -4 & 1 \\
0 & 1 & 0
\end{array}\right)+1 / 3\left(\begin{array}{ccc}
0.5 & 0 & 0.5 \\
0 & -2 & 0 \\
0.5 & 0 & 0.5
\end{array}\right)
$$

This operator is part of a family of convex finite difference operators that reduce the cross effects of the rectangular grid. It is as close as possible to a rotational invariant operator that performs better on this kind of rectangular-ordered data (Lindberg, 1990).

The CSD representation can be split into disjoint sets, namely the sink, the source, and the neutral set. They are disjoint in the sense that, at any given time, a channel can belong to only one of the sets. Next, we applied a single-pass algorithm to detect their disjoint connected components (Vincent and Soille, 1991). These can be singled out, and we can thus track their dynamics as growing, diminishing, or moving. The vector average of each one of these components produces a "center of mass" that can be used to trace the putative displacement of activity along the tissue, and this in turn can be used to obtain the instantaneous velocity of displacement (Manjarrez et al., 2007; Zapfe et al., 2015). The code was written in the open language Julia (Bezanson et al., 2017).

Data sets and programs as well as guidance for their use will be available upon request.

\section{Results}

As described previously (Ortiz and Gutiérrez, 2015), acute lesions in the entorhinal cortex in situ resulted in recurrent FRs between 250 and $600 \mathrm{~Hz}$ lasting $\sim 40 \mathrm{~ms}$ along the whole hippocampal CA region in vitro (Fig. $1 ; n=9$ slices from 7 animals). Interestingly, the DG presented low-amplitude FRs at the time when oscillations occurred in the CA3 region (Fig. $1 A, C$ ). Figure $1 A$ shows spontaneous activity recorded from a slice (Fig. $1 B$ ) in four selected electrodes within the DG and hilus and five electrodes along the CA regions. Field potentials were characterized by a dominant high frequency of $330-340 \mathrm{~Hz}$ along the hippocampal CA regions, which was also present in the DG, albeit with a lower power (Fig. 1D). In the hilus and CA1 area, an additional peak was observed at $160-170 \mathrm{~Hz}$ (Fig. 1D). An original recording of an event over the whole electrode array is presented in Figure 2.

We found systematic characteristics of the FRs in each of the different subnetworks as assessed by their duration, oscillation frequency, amplitude, and incidence of appearance (Table 1). Figure 3 depicts how these parameters are distributed along the CA region of the hippocampus and in the DG. It is noteworthy that FRs were recorded in the DG in only four of nine slices. The frequency, incidence, and duration of the FRs were similar along the CA region; however, the CA3 area displayed FRs with the highest amplitudes (Figs. 2, 3).
Figure $4 A$ shows the analysis of a characteristic event initiating in CA3b and evolving into a high-amplitude event spreading in both directions, toward CA1 as well as toward CA $3 \mathrm{c}$ and up to the DG. For a given experiment, the initiation site had a restricted distribution in CA3 that spread locally before propagating to distal, noncontiguous areas (Fig. 4A). Medial and distal parts of $\mathrm{CA} 3$, in both stratum pyramidale and radiatum, had the highest probability of occurrence of FRs (Fig. $4 B, C$; $n=9$ ). After originating in CA3 $(n=9)$, high-frequency activity propagated to contiguous regions of $\mathrm{CA} 3$, both along the pyramidal cell layer and stratum radiatum toward CA1, as well as to specific points in the hilar region and the DG (Fig. 4A, ms: 14, 18, and 22; Fig. 4D). The events appeared in CA1, hilus, and DG with a time shift that not always corresponded to the linear distance from the site of origin (Fig. 4D). Importantly, the propagation of events was not strictly topographically ordered. Indeed, events could appear in different nonadjacent areas without detectable continuous propagation between the activated sites. As a consequence, some areas proximal to the initiation site were activated later than more distal areas (Fig. 4D). It is noteworthy that in many instances, the activation of CA3 was followed by activation of the DG and hilus before the invasion of CA1. Likewise, some regions of distal CA3 or CA1 were activated before other CA3 regions contiguous to the site of origin (Fig. 4D; Movie 1).

CSDA allowed us to follow the sinks and sources of the oscillations with high spatiotemporal resolution. Importantly, we used the correction proposed by Lindberg (1990) for discrete second-derivative operators. This reduces a primarily unseen source of error in the computation of the CSDA, i.e., the possible error introduced by somatodendritic, nonorthogonal disposition of the cells on the microchip producing cross effects of contiguous electrodes of the squared grid. In particular, the currents associated with a given voltage transition could be well determined and related to a site of incoming information or where a given activity is originated. A representative event is depicted in Figure 5, where a voltage map is depicted, along with representative raw traces of the FR event in selected parts of the hippocampus (Fig. 5A1). The CSD maps of the FRs were composed by an initial sink in stratum radiatum of CA3 and a source in stratum lucidum (Fig. 5B). Moreover, this region is also the target for the long-range inhibitory cortical projections that may be disrupted by the cortical lesion. The initial slow component, which corresponds to the evolving slow potential during which fast frequency activity arises (Fig. 5A2), rapidly extended along CA3 and included an alternating arrangement of sinks and sources along the dendrosomatic axis from stratum lacunosum to stratum lucidum. The slow component of the event terminates with a sink/ source/sink arrangement around stratum pyramidale, suggesting strong and extended somatic inhibition. The spread of FRs after the initial slow phase is characterized by wave-like activation from the somatic region to the distal dendritic region, which can represent active propagation of action potentials from the somatic region, showing a source/sink/source arrangement. This rapid alternation likely reflects fast spiking activity of pyramidal cells (also seen under low- $\mathrm{Ca}^{2+}$ conditions) that gives rise to somatodendritic waves. During FRs, fast excitation from specific areas of CA3 spreads both to adjacent CA3 and CA1 regions and to the hilar region and the DG, probably by recurrent excitation. This yielded a pattern of propagating sinks/sources along the CA3 continuum. We computed the instantaneous velocities of the center-of-mass displacements, most of which were in the soma- 
A

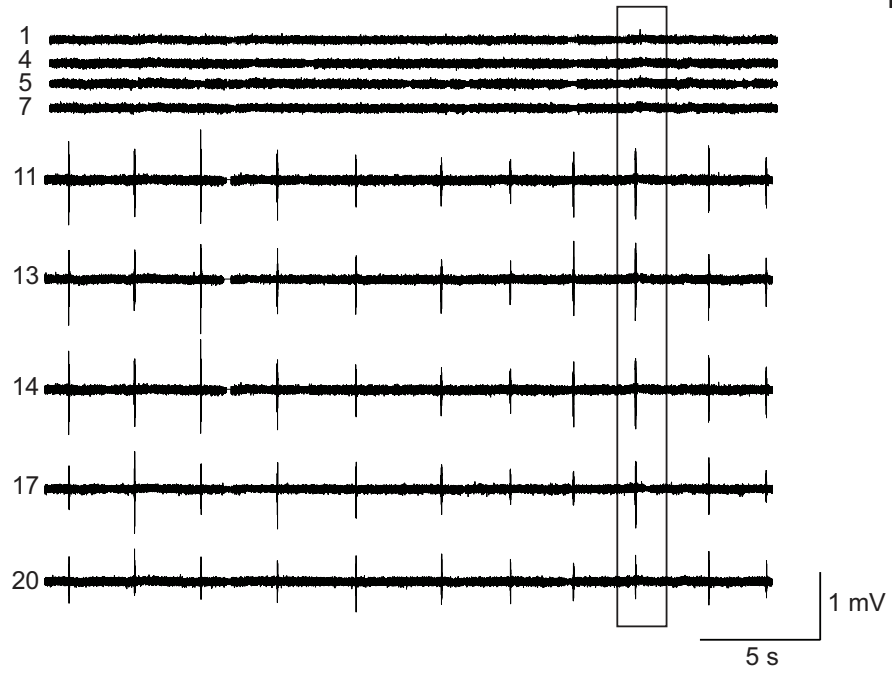

C

Raw

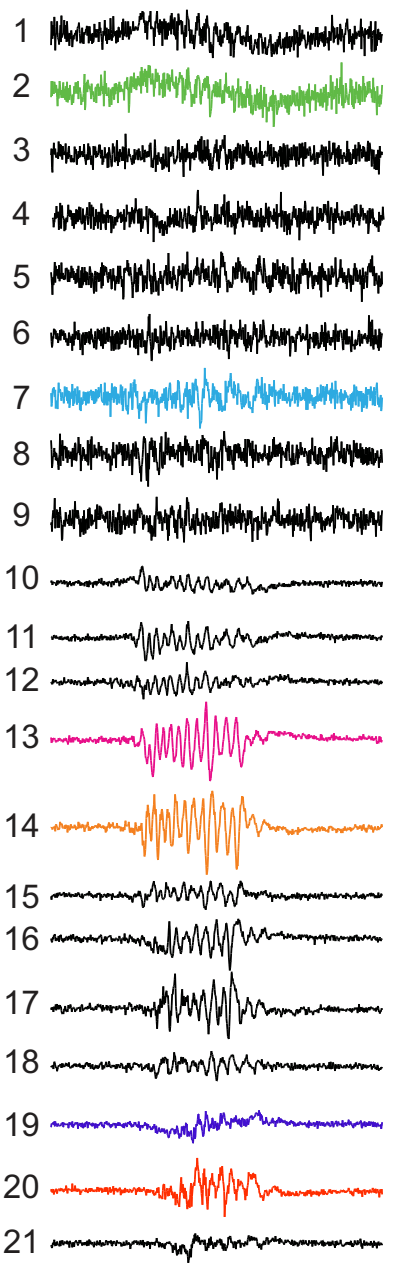

Filtered (250 - $600 \mathrm{~Hz})$
B
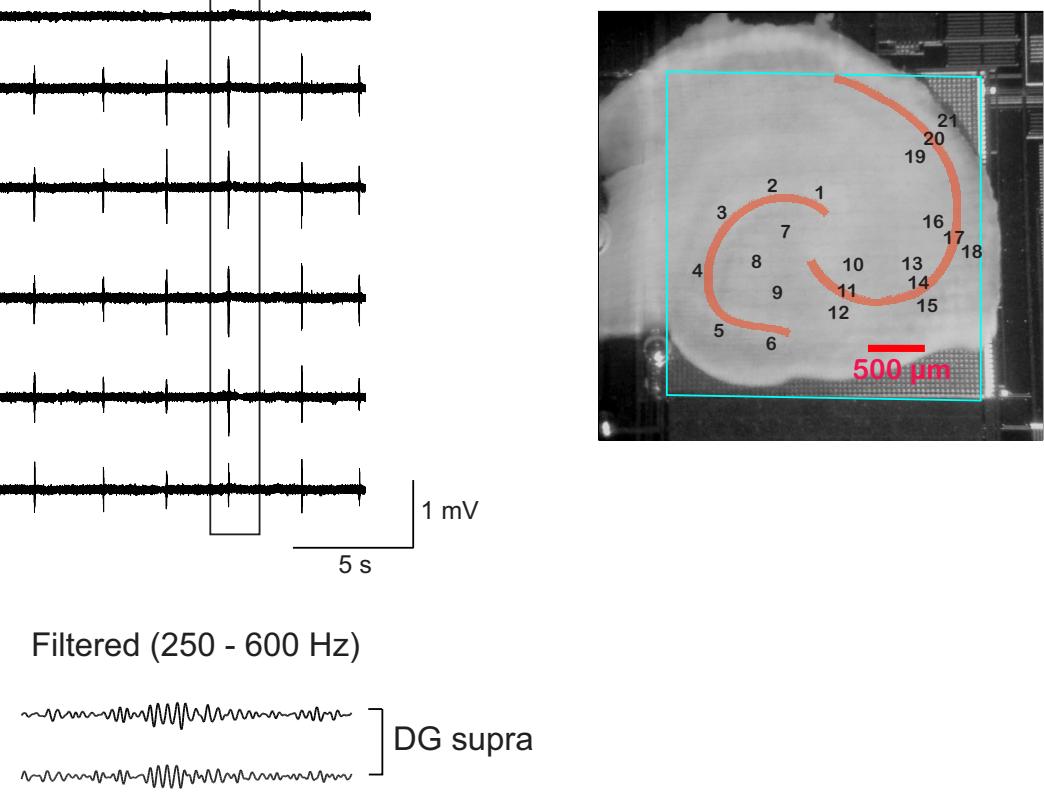

DG middle
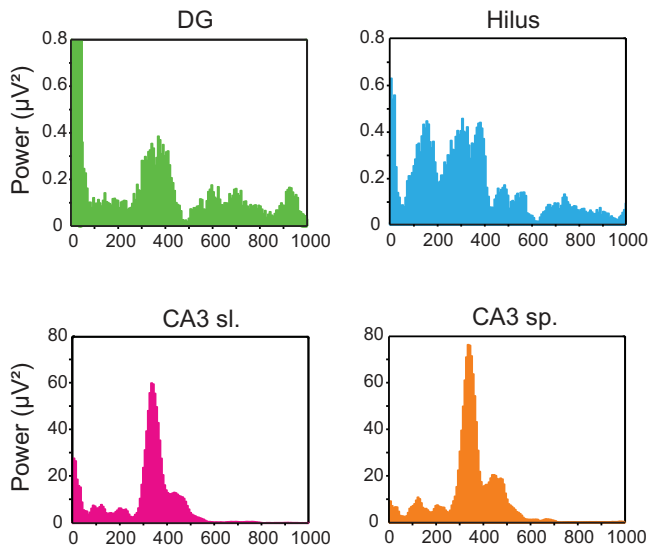

Medial
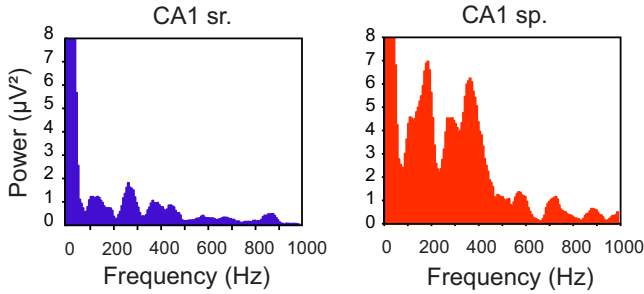

Figure 1. Fast ripple activity in the hippocampus. $\boldsymbol{A}$, Recurrent fast ripple events in different regions of the $D G$ and hippocampus proper. $\boldsymbol{B}$, Numbers to the left of the traces correspond to the positions depicted on the photograph of the hippocampus. $C$, Expanded raw and filtered traces of the event in the rectangle in $A$. Numbers indicate the recording position, as shown in $B$. Filtered traces $(250-600 \mathrm{~Hz})$ uncover the presence of fast ripples along the DG, hilus, and CA regions. These events with very high frequencies presented high amplitude in the $C A$ subregions $(n=9)$ but could also be recorded in the $\mathrm{DG}(n=4)$, albeit with low amplitude. The vertical calibration bar in microvolts applies traces 1 to 9 , both raw and filtered; the calibration in $\mathrm{mV}$ applies to traces 10 to 21. D, Power spectral analysis of the fast ripples recorded in the DG, hilus, stratum pyramidale (sp.) and stratum lucidum (sl.) of CA3, and strata radiatum (sr.) and pyramidale of CA1. Notice a distinctive peak at around $340 \mathrm{~Hz}$ in all the structures. 


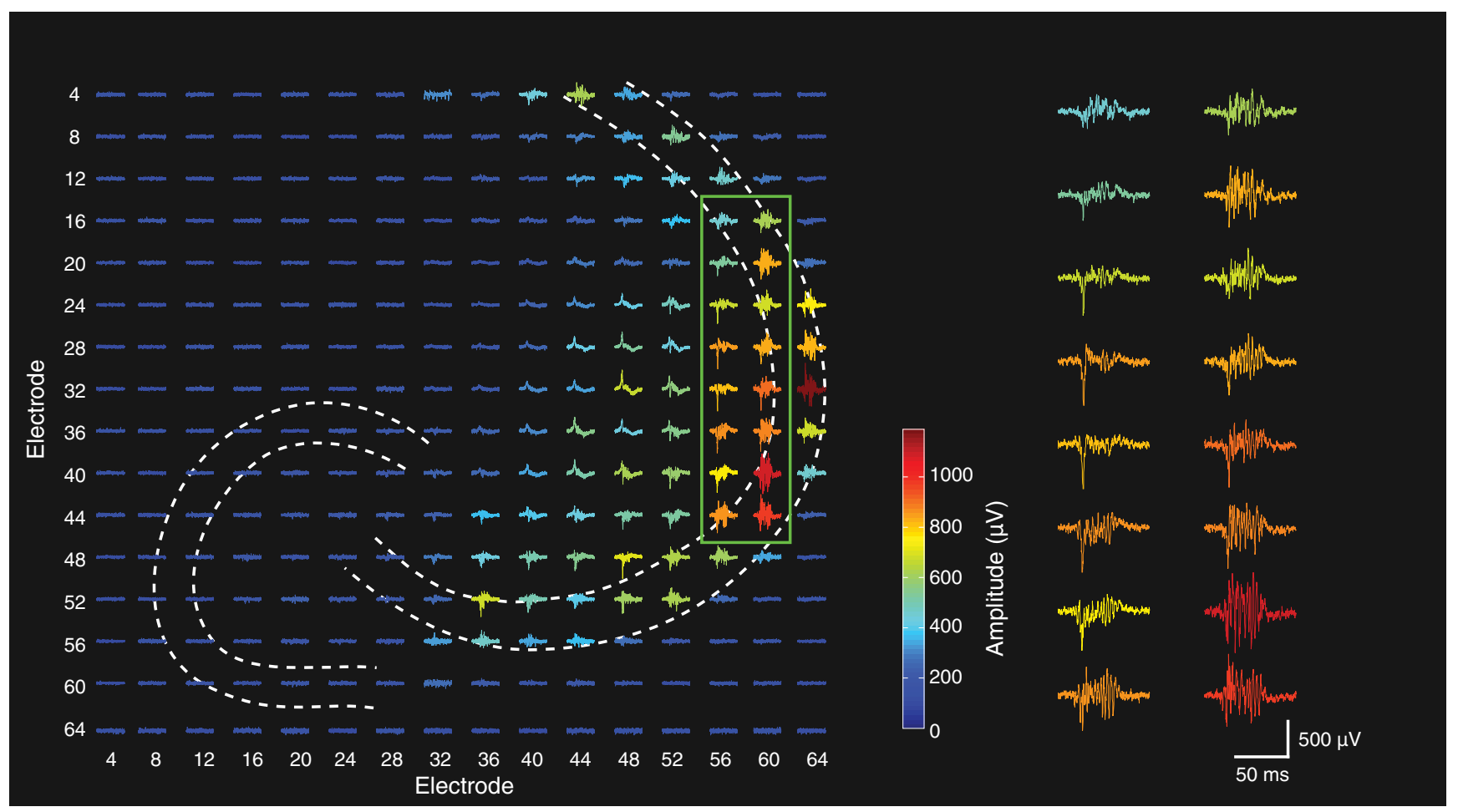

Figure 2. Simultaneous voltage recording in the entire hippocampus. Traces of $85 \mathrm{~ms}$ were taken from a $16 \times 16$ array out of the $64 \times 64$ microelectrode matrix for better depiction. Notice the strong presence of FRs in the strata radiatum and pyramidale of CA3 through CA1.

\section{Table 1. Characteristics of the fast ripples}

\begin{tabular}{lllll}
\hline & DG & Hilus & CA3 & CA1 \\
\hline Number of slices with FRs & $4 / 9$ & $4 / 9$ & $9 / 9$ & $8 / 9$ \\
Total number of recorded events & 308 & 316 & 977 & 876 \\
Mean number of electrodes that recorded the event & $42 \pm 11(25-75)$ & $97 \pm 61(21-171)$ & $469 \pm 45(332-708)$ & $365 \pm 81(96-651)$ \\
Area covered by the event $\left(\mathrm{mm}^{2}\right)$ & $0.075 \pm 0.02$ & $0.096 \pm 0.06$ & $0.83 \pm 0.08$ & $0.64 \pm 0.14$ \\
Incidence $(\mathrm{Hz})$ & $0.12^{*} / 2.7(0.004-1.14)$ & $0.15^{*} / 2.4(0.004-0.56)$ & $0.35^{*} / 1.85(0.004-7.39)$ & $0.34^{*} / 1.99(0.005-7.28)$ \\
Amplitude $(\mu \mathrm{V})$ & $74.1^{*} / 1.4(32.32-294.36)$ & $89.3^{*} / 1.3(27.7-320.5)$ & $259.7^{*} / 2.29(35.55-1988)$ & $218.6^{*} / 2.28(29.7-2126.8)$ \\
Duration $(\mathrm{ms})$ & $39.3^{*} / 1.6(7.69-154.43)$ & $35.1^{*} / 1.5(6.1-150.1)$ & $41.6^{*} / 1.46(8.4-156.65)$ & $42.2^{*} / 1.47(9.83-156.51)$ \\
Oscillation frequency $(\mathrm{Hz})$ & $338.7^{*} / 1.2(267.4-558.9)$ & $340.5^{*} / 1.2(253.7-569.2)$ & $334.3^{*} / 1.17(250.3-582.9)$ & $330.4^{*} / 1.16(256.9-576)$ \\
\hline
\end{tabular}

The geometric mean * SEM was used to describe each parameter measured. The range of the parameters is shown in parentheses.

todendritic direction (Movie 3). After analyzing $>400$ trajectories, we obtained the range of propagation velocities of the center of mass, which ranged from 0.05 to $0.25 \mathrm{~m} / \mathrm{s}$ (Fig. 6). Using selected long trajectories that repeat over time, we obtained a value of the instantaneous velocity of somatodendritic wave-like activity of $0.16 \mathrm{~m} / \mathrm{s}$, whereas the instantaneous velocity in the DG-hilus-DG interactions was of $0.27 \mathrm{~m} / \mathrm{s}$. In contrast, the velocity of short, often discontinuous trajectories in the CA3-CA1 direction yielded a velocity of $0.21 \mathrm{~m} / \mathrm{s}$.

Interestingly, we also observed propagation of activity toward the hilus and DG. The granule cell layer and hilus presented sinks/sources, subsequent to the initiation of fast events in CA3 (Fig. $5 B$ ) but which did not always coincide in time or site of origin within CA3. Sources and sinks alternate in the stratum pyramidale region throughout the event and along CA3 and CA1. Accompanying these, stratum lucidum and stratum oriens also alternate sink and sources in a fast manner, switching sources and sinks within $2 \mathrm{~ms}$ in defined patches of stratum pyramidale. Fast dynamics of sink/source switches in a patchy manner suggests either alternate unitary spiking activity or activation of defined microcircuits (several neurons), probably relaying information along the CA3 region and to the DG. Alternatively, these patches represent "out-of-sync" sources of activity that appear when inhibition, which controls the synchrony of the network, is disrupted (Movies 2, 3).

To determine whether FRs in the DG and CA1 were caused by oscillations in CA3, we applied the Granger causality test with which we determined all significant interactions $(p<0.05)$ between signals recorded from CA3 to DG and to the hilus and from CA3 to CA1 (Fig. $7 A, B$ ). Since the test uses a multivariate regression model, with the variables being all the signals from the electrodes that recorded the event, the signal of each electrode was tested against the signal of every other electrode to determine which signal best predicted the signal recorded by the other electrode. Both signals can contain information that predicts the other signal to a certain degree. The interaction can, therefore, be bidirectional or unidirectional. Figure 7, $A$ and $B$, shows significant interactions in a topographic map that indicates the coordinates of the electrodes that recorded the event (gray squares) and the interactions between them (colored lines connecting the squares). As expected, most interactions occur within CA3, both at the pyramidal and radiatum layers and between CA3 and CA1. Fewer significant interactions are present between CA3 and the DG, between CA3 and the hilus, between the hilus and the DG, or 


\section{A}
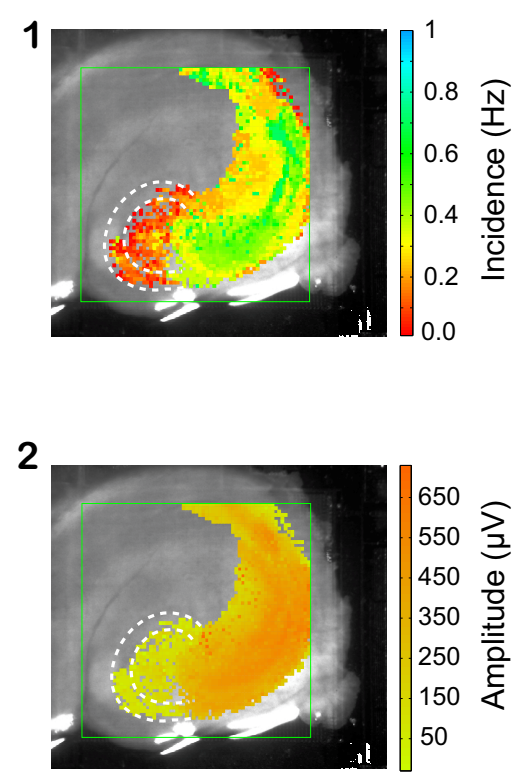

3

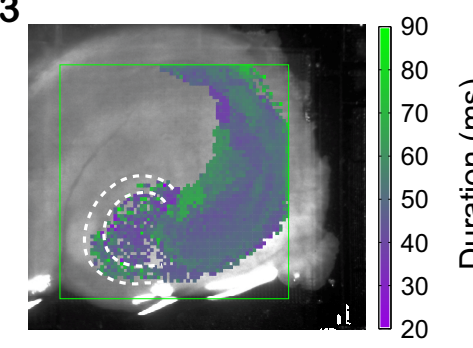

4

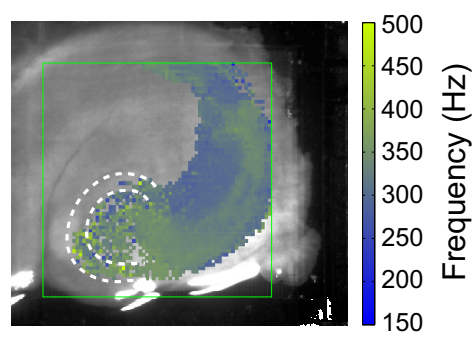

B
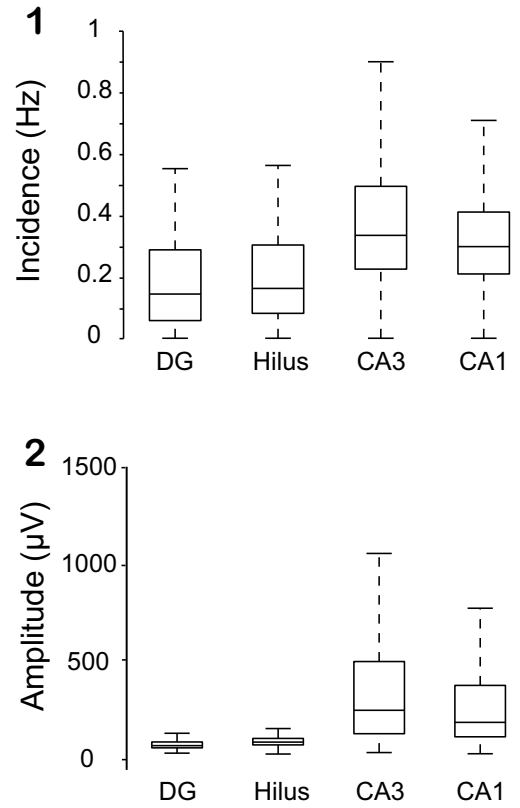

3

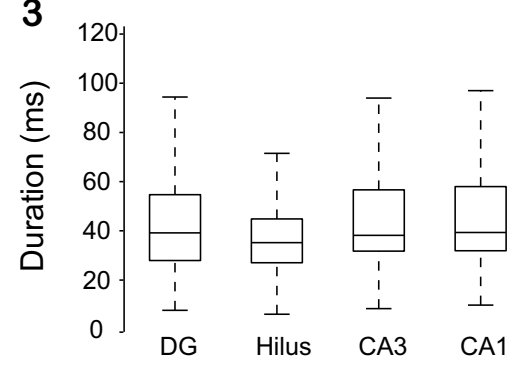

4

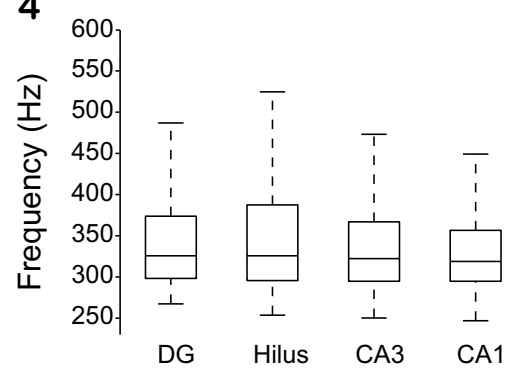

synaptic transmission is needed to recruit ensembles that fire out of phase and thus generate high frequencies. On the other hand, low-calcium ACSF did not prevent a number of neurons along the CA area from firing spontaneously (Fig. 7C,D; Movie 4).

\section{Discussion}

We have shown that the disruption of corticocortical connections along the dorsoventral axis of the entorhinal cortex in situ disinhibits the functional architecture of the hippocampus, which is reflected in the generation of FRs in CA3 (Ortiz and Gutiérrez, 2015). Here we studied their site of origin as well as their patterned spread using dense microelectrode array recordings. In particular, we explored whether FRs recorded in CA3 were followed by FRs in the hilus and DG, which may indicate backpropagation of activity from CA3, eventually producing a feedback loop.

Our recordings were conducted with a MEA under submerged conditions. Although evoked activity can be recorded with this technology and epileptic activity can be induced with bicuculline or 4-AP (Ferrea et al., 2012), network oscillations are usually absent because of limited oxygen availability (Morris et al., 2016) and have not been reported using this technology. Using a high velocity of perfusion with oxygenated ACSF (Hájos et al., 2009), we were able to study recurrent high-frequency oscillations in the rat hippocampus in a model of traumatic brain injury. Indeed, because the DG regulates the flow of normal and pathological information between the entorhinal cortex and the hippocampus (Buzsáki et al., 1983; Heinemann et al., 1992; KrookMagnuson et al., 2015), post-traumatic alterations can be reflected in the DG-CA3 synapse (Heinemann et al., 1992; Santhakumar et al., 2003). As described previously (Buzsáki et al., 1991), ictal events in the hilus or the DG had a smaller amplitude than those in the CA regions and seemed to depend on their presence in the CA3 area, which can in turn backpropagate them to the hilus and the DG. We extend these observations by showing that oscillatory activity and not just ictal spikes

Figure 3. Statistical parameters of the fast ripples. $A$, Topographic maps of the different parameters measured in $C A(n=9)$ and $D G /$ hilus $(n=4)$. Values in the color scale are superimposed to a photograph of the hippocampus to signal incidence $(\boldsymbol{A} \boldsymbol{1})$, amplitude (A2), duration (A3), and frequency $(\boldsymbol{A} 4)$ of the fast ripples. Note that the middle portion of the DG is not invaded by the events. The green square on the photograph denotes the MEA recording area. $\boldsymbol{B}$, Whereas frequency $(\boldsymbol{B} 4)$ and duration $(\boldsymbol{B} \mathbf{B})$ of the events are similar in all structures, the incidence (B1) and amplitude $(\boldsymbol{B} 2)$ of the events are significantly higher in $C A$ with respect to $D G$ and hilus. Moreover, these data do not follow a normal but a log-normal distribution.

within the DG. Group results from the slices that presented FRs in the DG and hilus $(n=4)$ revealed significant Granger causality between different areas (Fig. $7 B$ ). Indeed, there were strong bidirectional interactions between the hilus and CA3 and significant interactions between CA3 and the DG. These results suggest that activity starts in CA3 from where it propagates to CA1 and to the DG/hilar region.

Finally, we analyzed the effect of perfusing a low-calcium $(0.2$ $\mathrm{mm}$ )-containing ACSF on the FRs. Under this condition, the generation of population activity is prevented, indicating that chemical can propagate to the hilus and the DG.

Our bidimensional CSDA allowed us to analyze the whole hippocampus during the entire event at a very high spatiotemporal resolution. The distribution of sinks and sources was consistent with the laminar disposition of cell bodies and dendrites in the hippocampal regions. Interestingly, sink/source/sink arrangements that appeared in stratum pyramidale propagated to CA1 and to the hilus and DG, where sinks/sources could be observed during FRs after the slow sink in stratum radiatum had 

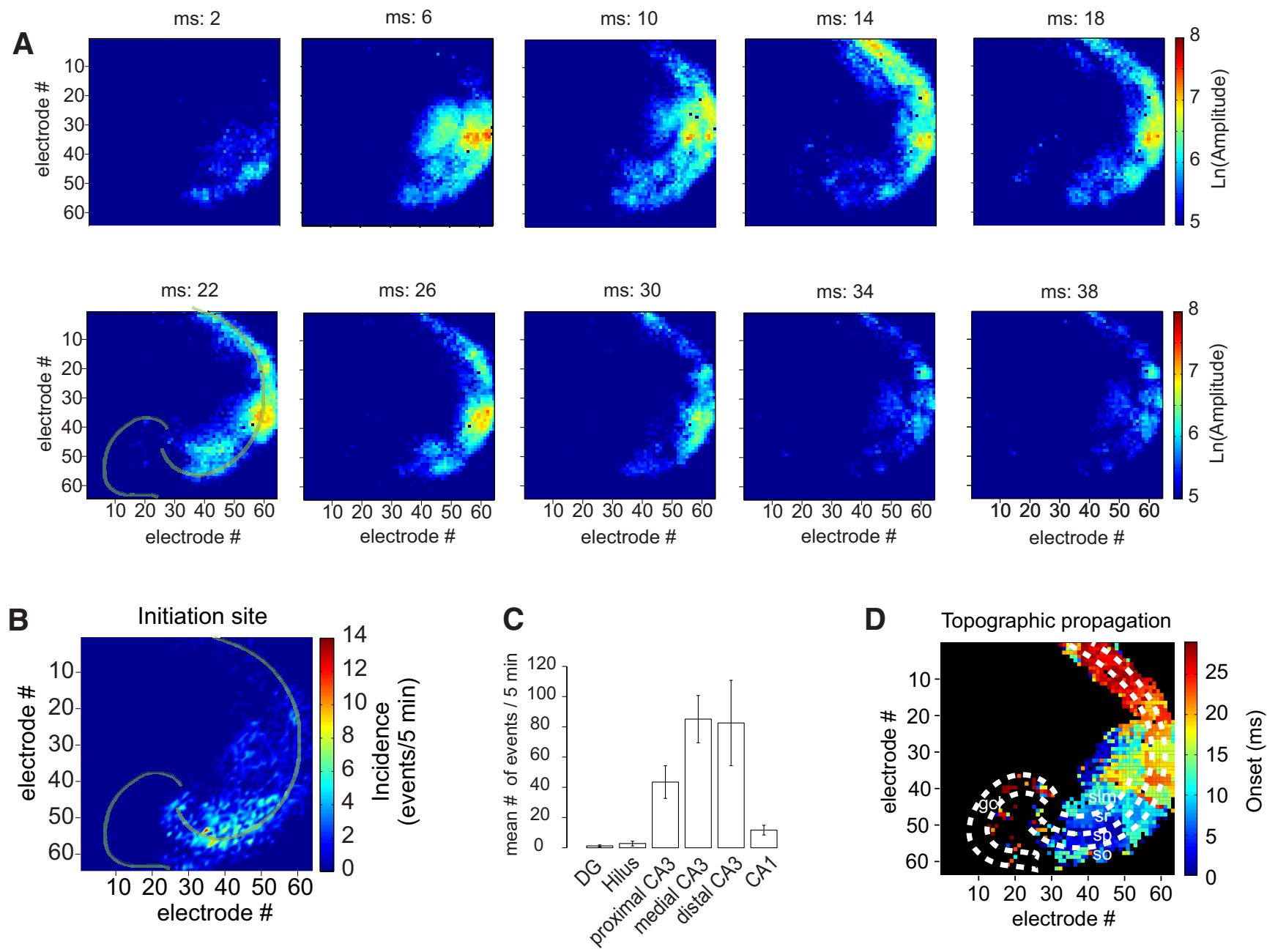

Figure 4. Propagation of the fast ripples. $\boldsymbol{A}$, Propagation sequence of a representative event. Fast ripples normally initiated in area CA3 and spread to CA1 and to the hilus/DG. $\boldsymbol{B}$, An analysis of the incidence of the initiation site showed that fast ripples initiated mainly in medial and distal CA3, with no statistically significant differences between these areas. $C$, The incidence distribution through the different hippocampal areas. D, Depiction of the progression of the event, whereby the color indicates the time at which the electrodes detected the event (time- color coding on the right scale). Note that the invasion of electrodes by fast ripples presented a time gradient from CA3 to CA1 and DG, although isolated regions could present them in an apparent spatiotemporally disorganized manner.

dissipated. Although we observed sources/sinks and sinks/ sources in the inner molecular layer/hilus of the DG, we cannot relate them to slow synaptic activation of hilar mossy cells (Buzsáki, 2015), which are not likely to generate a field potential because of the lack of a parallel arrangement of the cells (Scharfman, 2016). Rather, it was not until CA3 displayed FRs that specific regions of the DG/hilus displayed similar activation sequences. The mode of transfer of information to the DG may thus involve recurrent activity from CA3 to the hilus (Gafurov and Baush, 2013) and also possibly antidromic invasion of the DG after activation of distinct sites within CA3. As reflected by a crosscorrelation analysis, the conduction velocity of the FRs in the DG-to-CA3 direction, as measured in the orthogonal matrix, was $0.28 \mathrm{~m} / \mathrm{s}$. These values are in the range of those previously reported for mossy fiber transmission $(\sim 0.3 \mathrm{~m} / \mathrm{s}$; Henze et al., 1997; Schmidt-Hieber et al., 2008; Vivar et al., 2012). Transmission of FRs from CA3 to DG may involve synaptic (via mossy cells) and nonsynaptic modes of propagation (Buzsáki et al., 1991); the latter may be mediated either by gap junctions or by ephaptic interactions (Kasyanov et al., 2000; Simon et al., 2014). In our experimental model, FRs disappear under low-calcium conditions, indicating a crucial role of chemical synaptic trans- mission in recruiting a minimal number of cells to function as a trigger ensemble.

Interestingly, the high spatiotemporal resolution of our recordings uncovered that large areas were activated almost simultaneously both in the somatic and dendrite-projecting regions. Indeed, rather "big patches" of CA3 were activated whenever a FR appeared, covering an average area of $0.8 \mathrm{~mm}^{2}$ in the CA1-CA3 regions and $0.07 \mathrm{~mm}^{2}$ in the DG. Feedback inhibition from CA3 to DG could account for this topographic constraint of reactivation of the DG. Population bursts of CA3 pyramidal cells during hippocampal sharp waves can produce both excitation and inhibition of granule cells (Buzsáki, 1986; Scharfman, 1993, 1994; Kneisler and Dingledine, 1995; Ylinen et al., 1995; Penttonen et al., 1997). Additionally, restricted sinks/sources observed in the hilar region and inner band of the granule cell layer could represent their activation by volume-conducted potentials from the mossy fibers (Kasyanov et al., 2000). The latter may be transmitted in accordance with their resonance properties (Franco et al., 2016), and this can arise from CA3 cell activity electrically invading the mossy fiber axons by volume interactions or through gap junctions (Vivar et al., 2012; Simon et al., 2014). 


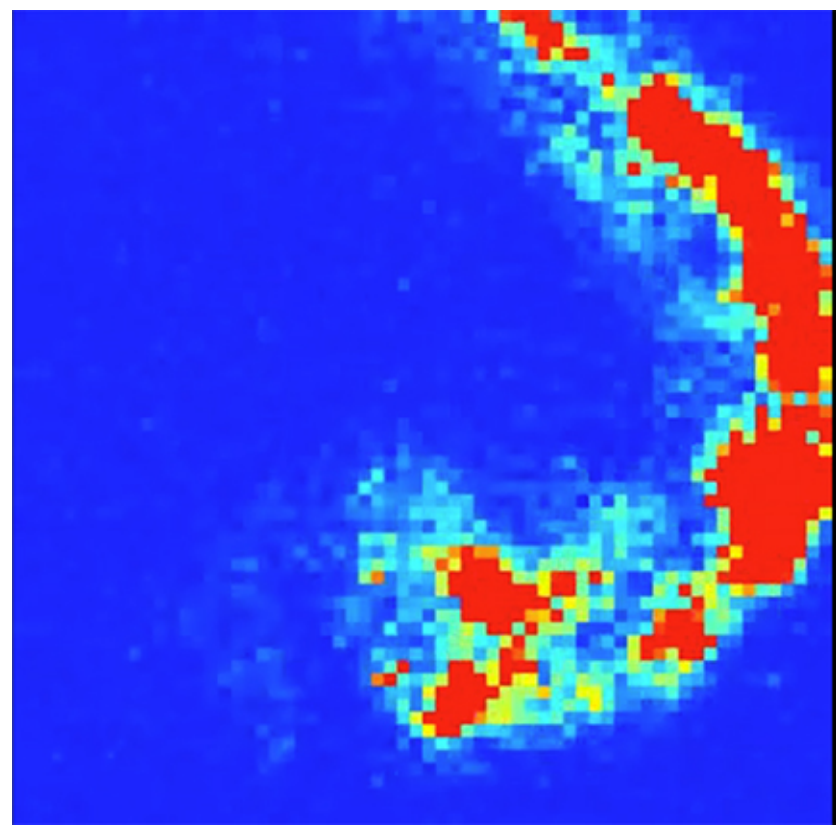

Movie 1. LFP.mp4. Fast ripple propagation. Shown is a representa- $\square$ tive event that lasts $\sim 40 \mathrm{~ms}$ and which is displayed 150 times slower in the video. The local field recordings show the initiation and propagation of a FR along CA, hilus, and DG. Warm colors indicate higher amplitude of the local field potential (measured from peak to peak) at a given time during the event. Notice that the event begins in the pyramidal layer of

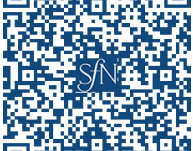
distal CA3 and propagates toward the dendritic layer, as well as to the pyramidal layer of CA1, medial and proximal $C A 3$, the hilus, and the DG. Fast ripples can reach the DG during their early propagation, albeit with lower amplitude, in the hilus and DG.

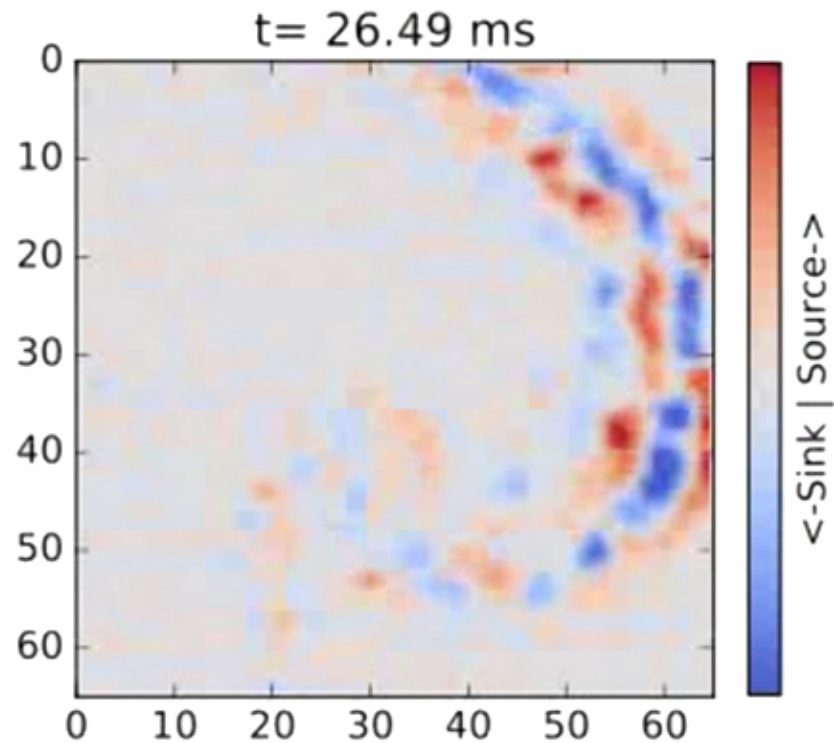

Movie 2. CSDA.mp4. High spatiotemporal analysis of the current $\square$ source density of a FR event. The movie displays 1461 frames at a frequency of $16.6 \mathrm{fps}$. The interval between frames is $0.14 \mathrm{~ms}$. Both red (sources) and blue (sinks) scales are in arbitrary units.

Under physiological conditions, an organized and synchronized layout of sinks and sources has been previously presented along the transversal axis when sharp waves occur (Both et al., 2008; Buzsáki et al., 2012). In the case of FRs, a disorganized

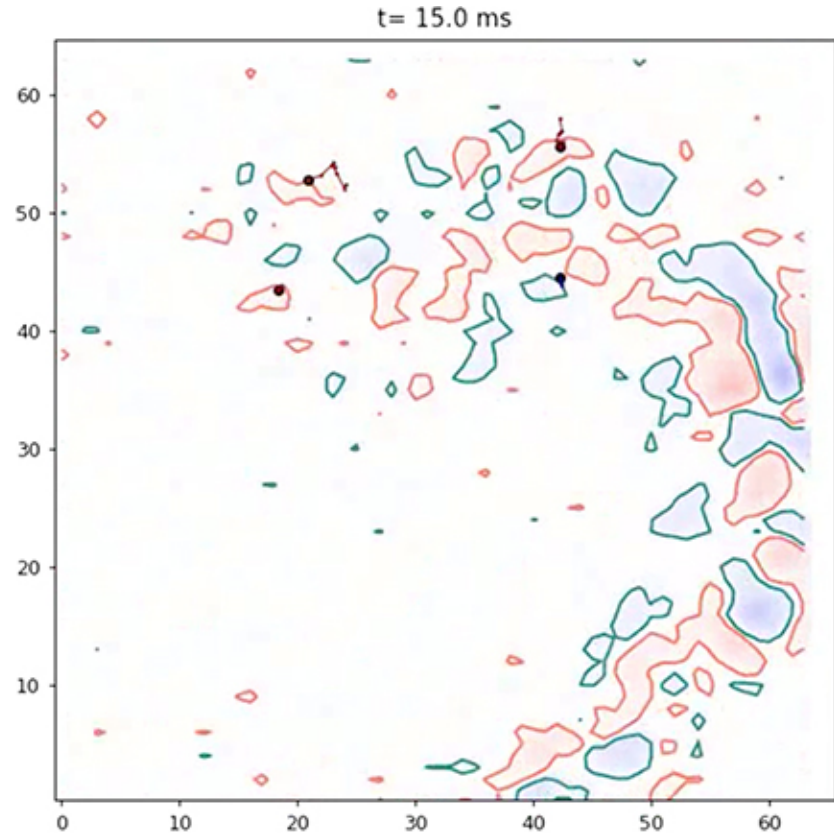

Movie 3. CSDAcomponents.mp4. The determination of disjoint $\square$ components of sinks and sources and the estimation of their trajectory are shown. After computing each component or "patch" (see Materials and Methods), vector averaging over each one of these components produces a putative center of mass, which can be used to trace the displacement of the component. We obtained length and instantaneous velocity of such a vector. In this movie, only some samples were included to avoid graphical saturation, but all components can be followed. Note the somatodendritic direction of some trajectories, as well as the appearance of new components in the CA1-CA3 direction. Importantly, DG- hilus/CA3 trajectories appear during the FRs.

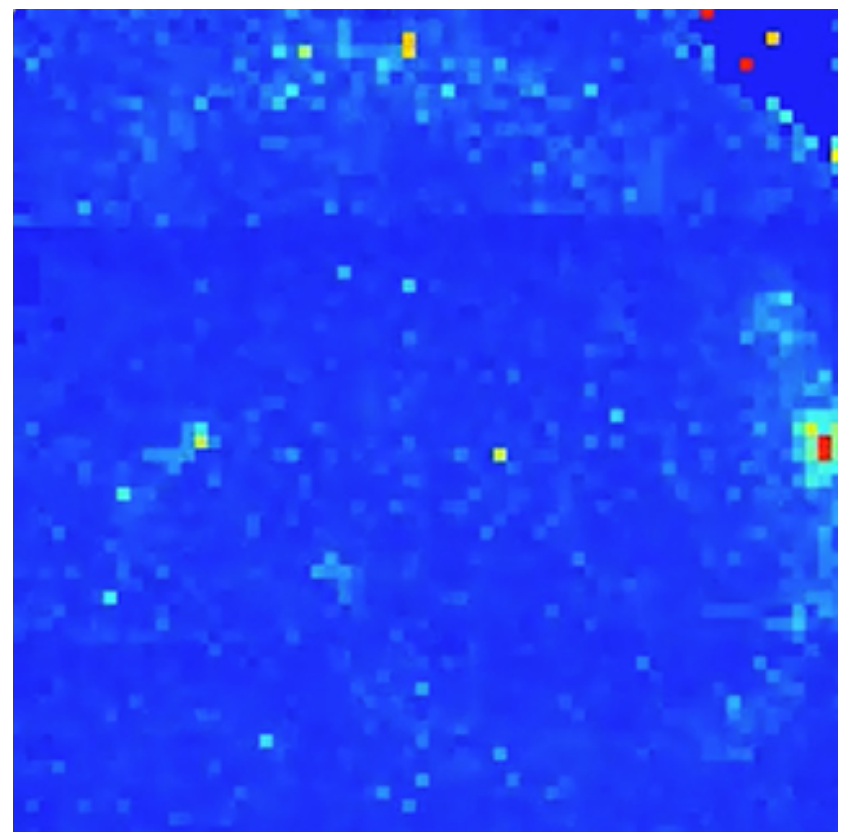

Movie 4. Low $\mathrm{Ca}^{2+} \cdot \mathrm{mp} 4$. Shown are voltage recordings under low$\mathrm{Ca}^{2+}$ conditions. Fast ripples are prevented under these conditions, but action potentials can still be recorded along the hippocampus.

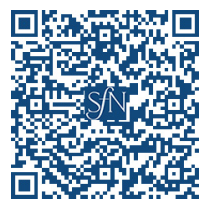


A1

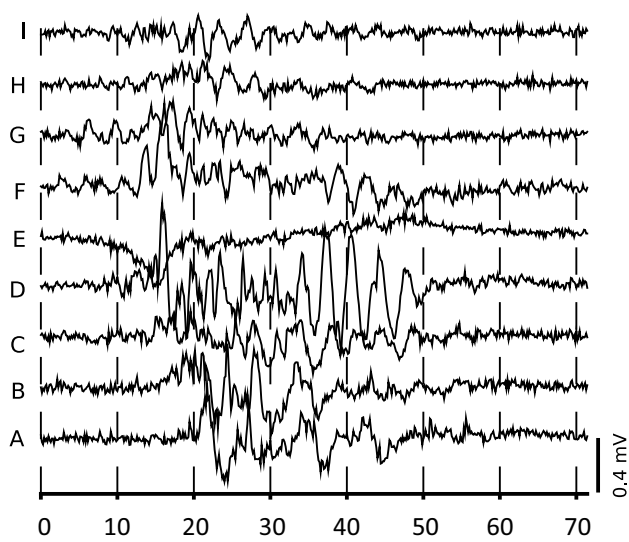

A2

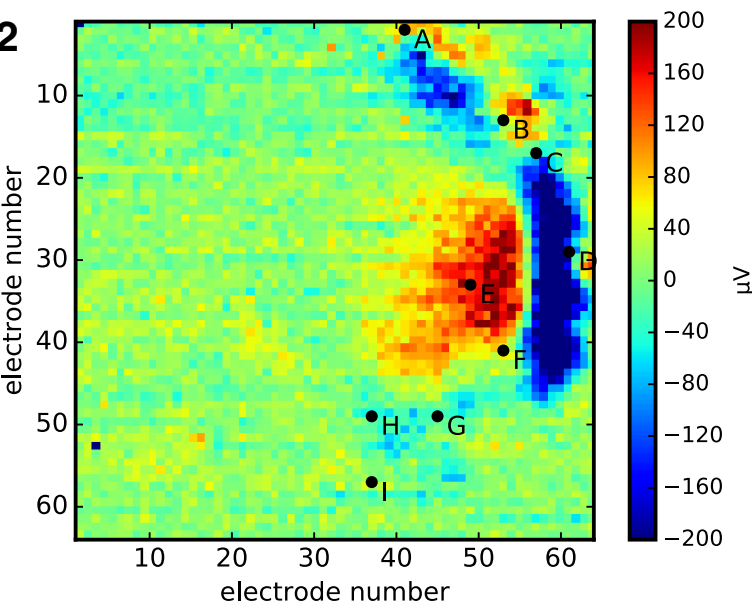

$\gtreqless$

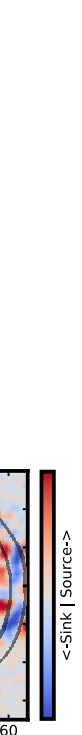

B
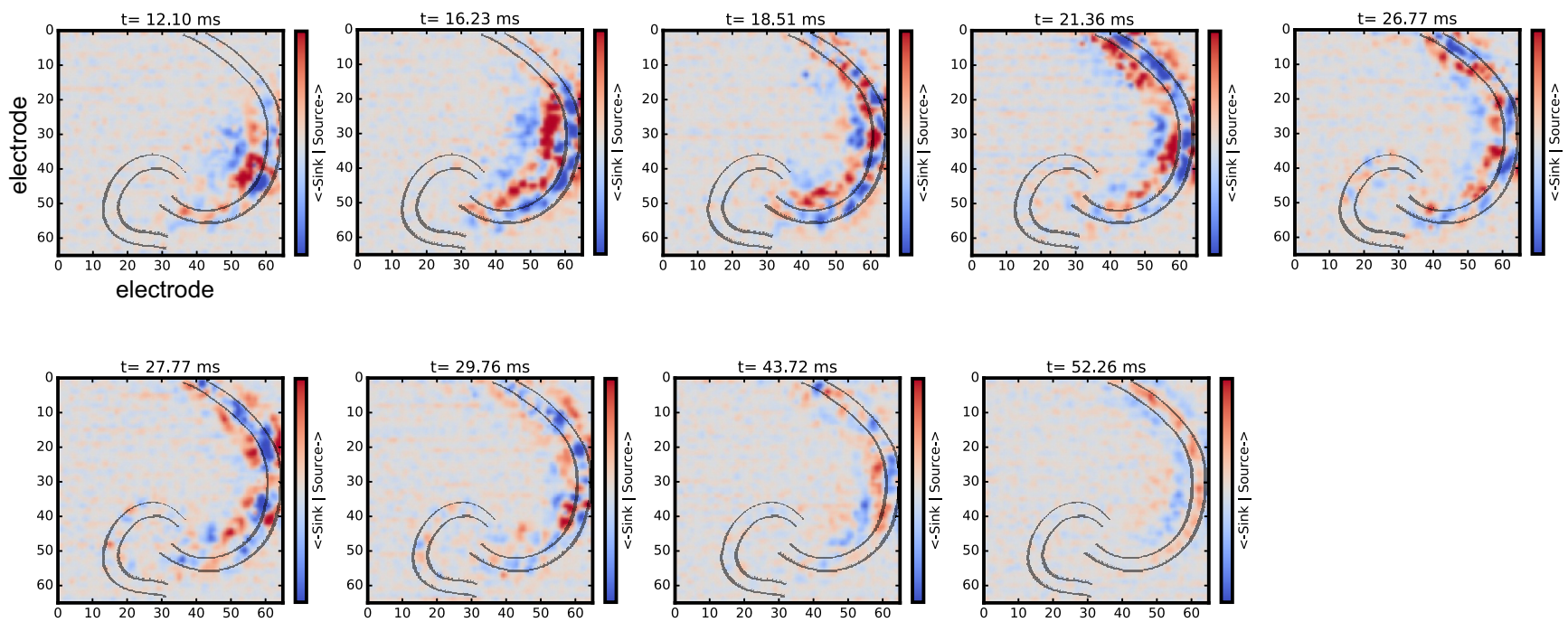

Figure 5. Current source density analysis. A1, A fast ripple event at an expanded time scale, whereby high frequencies appear on a slow-developing component. $\mathbf{A 2}$, A color map (in voltage) of the traces in $\boldsymbol{A}$. The locations where the selected traces in $\boldsymbol{A} \boldsymbol{1}$ were acquired are signaled with the letters on the color map. $\boldsymbol{B}$, Time sequence of the CSD dynamics throughout a fast ripple at a high spatiotemporal resolution. Events initiated in CA3, often in different sites with a sink in the distal dendritic zone and alternate sink/source regions up to stratum oriens (frames at $t=12.1$ and at $t=16.23$ ). This slow component was followed by high-frequency activity that showed discontinuities along the CA3 that spread to CA1, after which patches of sink/source signals appeared in CA3 with concurrent signals in the DG ( $t=26.77-29.76 \mathrm{~ms})$. The patchy nature of the signals suggests activation of discrete zones of CA. The later phase of the slow component was characterized by a source along CA stratum pyramidale and sinks in strata radiatum and oriens. The size of the figure corresponds to the whole active zone of the recording matrix (see Materials and Methods).

layout of sinks and sources is observed along the transversal axis suggesting a disruption of the mechanisms involved in the coordination and orderly propagation of physiological highfrequency oscillations, particularly synaptic inhibition.

Importantly, despite the spread of the local field potentials (LFPs) along the CA regions, we show a discontinuity of "active spots" along CA3, hilus, and the DG, which only CSDA can reveal, as source density is spatially confined (Buzsáki et al., 2012). One-dimensional estimation of CSD (typically along the somatodendritic axis) is possible only in a situation in which the LFP varies little in the lateral direction. This assumption is often not satisfied when the layers curve (Herreras, 2016). In our case, we used two-dimensional estimation of the CSD, using equally spaced high-density electrodes in both vertical and horizontal directions. We implemented a method to measure the displacement velocity of the current densities by using the highest vectorial current within a disjoint component as the center of mass. The quantitation of instantaneous velocities of the center of mass reflects short-distance field effects so that even displacement of sets of current densities within the cells' somatodendritic axis can be observed. The origin of such events is probably related to synaptic activation of distinct sets of cells (see appearance incidence in Fig. 4). Once the events are originated, they can travel in a wave-like manner, mainly in the somatodendritic axis, restricting them to short trajectories. Interestingly, lateral displacement of current density along the CA region is not continuous. Analyzing propagation of ictal activity, albeit in a neocortical circuit, Wenzel et al. (2017) proposed that the progression of the activity follows preexistent pathways but can vary in time, depending on local inhibition. Indeed, CSD conduction velocities differ between events. Importantly, measurements were conducted on spontaneous events, which lack simultaneous activation of a big 
A
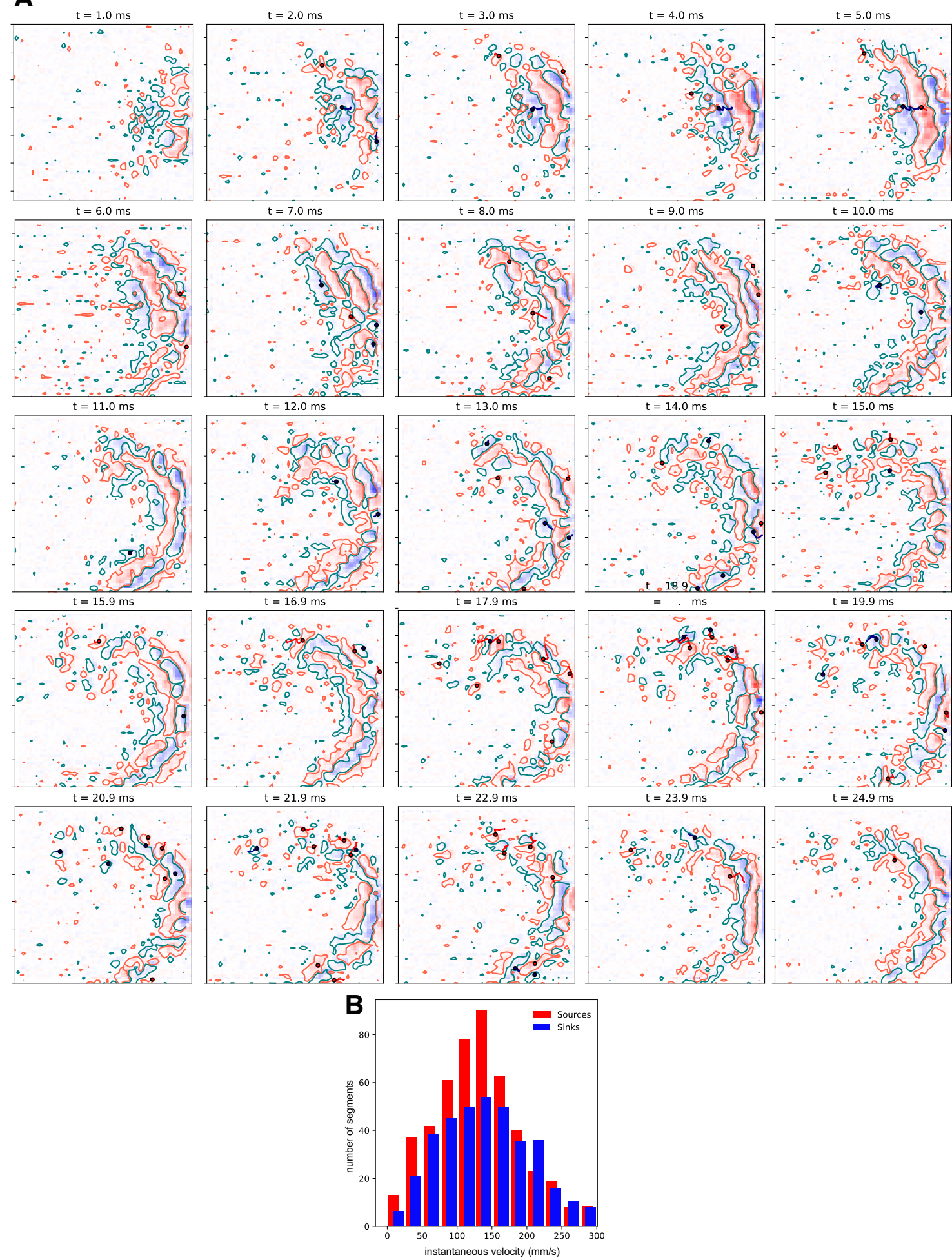

Figure 6. Fine topographic evolution of current source density in time. A, Snapshots of the sinks and sources obtained every millisecond, during the first $25 \mathrm{~ms}$ of a fast ripple event. Patches in red are sources, and patches in blue are sinks. The boundaries of the components were obtained by setting a threshold of the current density above the noise level, yielding disjoint components that can appear, disappear, or move. Contrary to local field potentials, which obscure the micrometer resolution of activity, current densities can be measured with a resolution $<20 \mu \mathrm{m}$ and followed in time. Trajectories of the disjoint components were traced by obtaining the center of mass at high frequency. Thus, instant velocities could be obtained from this analysis. Interestingly, displacements of sinks and sources can be observed within the DG-hilar region, close to the proximal part of CA3. The dynamics of the wave-like activity can be better observed in supplemental Movie 3. B. Histogram depicting the distribution of instantaneous velocity measurements. Ordinates are the number of displacement segments for each instantaneous velocity range (bin, $0.025 \mathrm{~m} / \mathrm{s}$ ). The resolution of the center-of-mass computation was of $\sim 10 \mu \mathrm{m}$ because it is very sensitive to the differences of value of the CSD in the neighboring electrodes. 
A

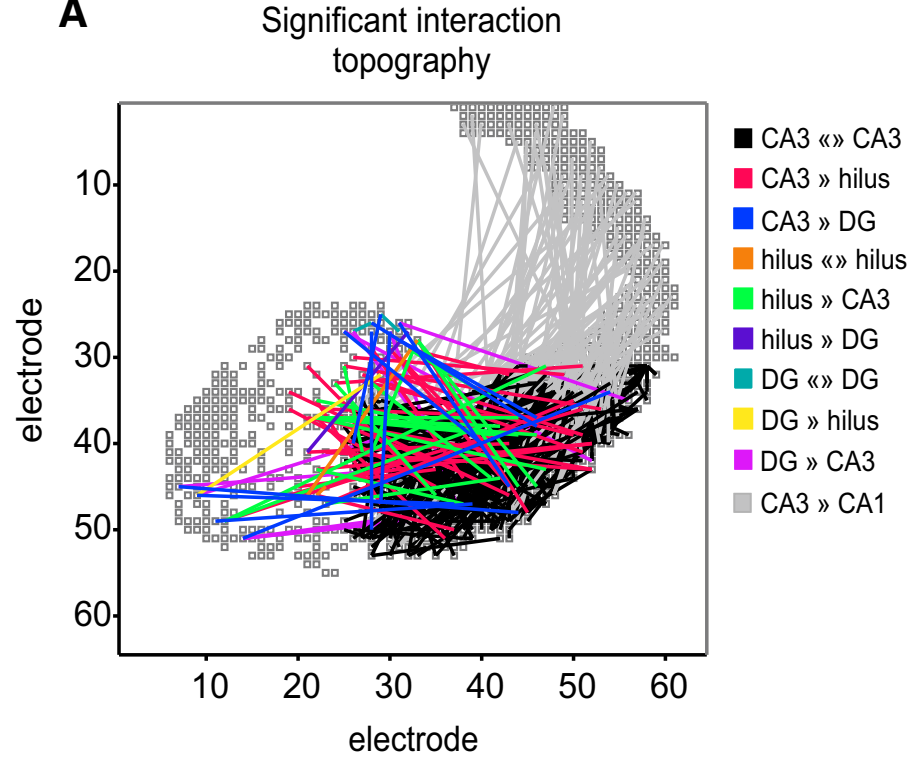

C

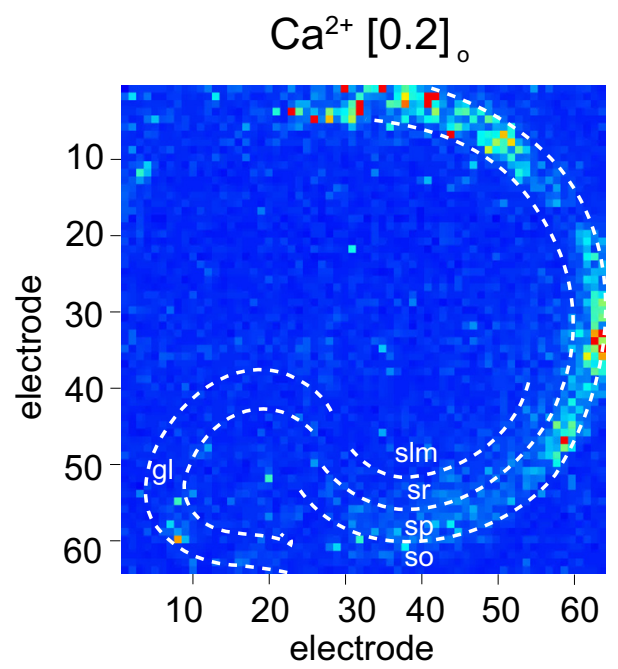

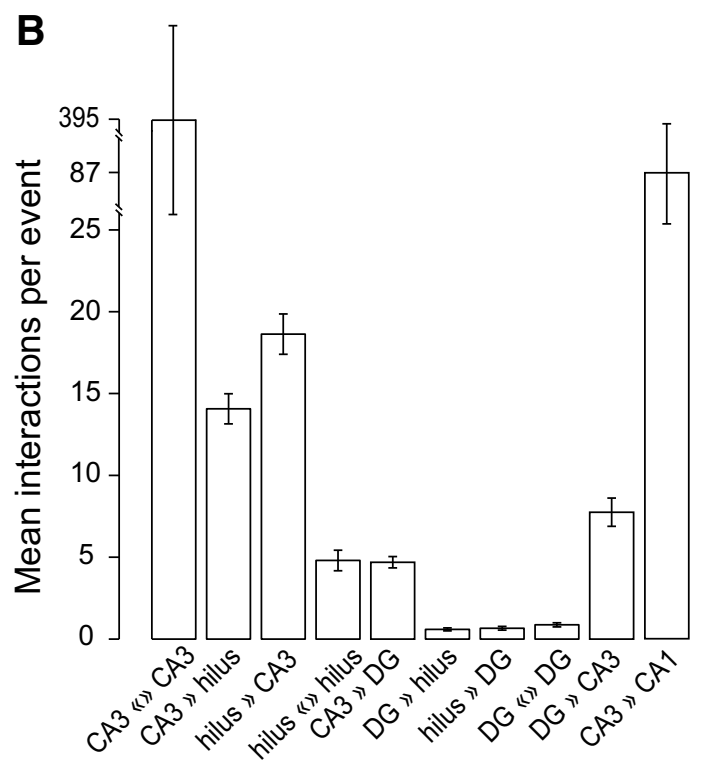

D

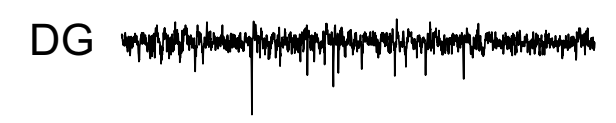

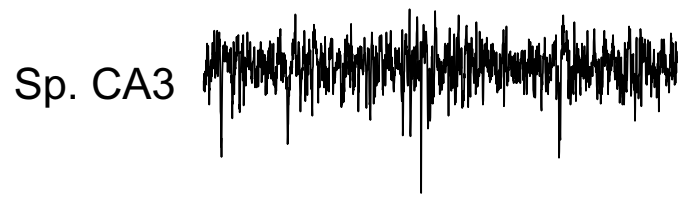

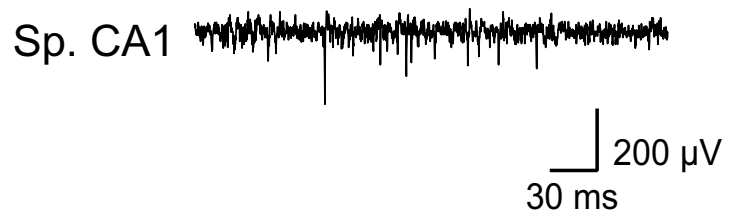

Figure 7. Granger causal interactions and calcium dependence. $A$, Bidirectional interaction of CA3 and DG and interactions from CA3 to CA1 in a representative experiment. Fast ripples were recorded in 833 electrodes, of which 581 were in $C A 3,230$ were in $C A 1$, and 22 were from the dentate gyrus and hilus. Related electrodes/sites were joined by lines. B, Mean Granger causal interactions $(p<0.05)$ were computed per fast ripple event. Note that most Granger causality interactions happen between CA3 electrodes; however, CA3 causes fast ripples in the $D G$, and the DG causes fast ripples in CA3. C, Voltage map showing the remaining multiunitary activity in the pyramidal and granular cell layers in a low-calcium ( $0.2 \mathrm{~mm}$ ) recording solution. FR activity ceased, indicating its dependence on chemical synaptic transmission. $\boldsymbol{D}$, Representative multiunitary activity recordings from the DG granule cell layer and CA3 and CA1 pyramidal layers.

number of recruiting fibers in a given tract (Schaffer collaterals or mossy fibers) by stimulation. The range of velocity values of all trajectories (displacement of center of mass) observed in our experiments yielded magnitudes similar to those of current source density components previously reported using $2 \mathrm{D}$ profiles $(0.3-0.4 \mathrm{~m} / \mathrm{s}$; Novak and Wheeler, 1989), which is slightly slower than mossy fibers' and Schaffer collaterals' conduction velocity $(0.4-0.5 \mathrm{~m} / \mathrm{s}$; Novak and Wheeler, 1989).

This type of discontinuous spread of sinks and sources may correspond to the disruption of the precise temporal relationship between firing of a cell or groups of pyramidal cells and population ripples in the hippocampus of epileptic rats (Foffani et al.,
2007). Also, it can be possible that some neuronal aggregates function as pacemakers (Wittner and Miles, 2007) or that there is activation of parallel channels of processing along the CA hippocampal region (Soltesz and Losonczy, 2018).

In contrast to the interictal spikes obtained in subcortically denervated hippocampus, wherein sprouting can result in a shift of balance of excitation versus inhibition (Buzsáki et al., 1991), our preparation uncovers a functional disinhibition caused by acute cortical but not hippocampal damage. Although full characterization of such disinhibition has still to be conducted, it has been suggested that inhibitory projections from the entorhinal cortex act as a temporally precise disinhibitory gate of information and may participate in plasticity (Basu et al., 2016). This 
plasticity, which develops after the corticocortical lesion, seems to constitute an irritating focus that may underlie epiletogenesis after traumatic brain injury (Ortiz and Gutiérrez, 2015). The spatiotemporal resolution of CSDA data is much higher and specific than that obtained by analyzing field potentials. Indeed, CSDA yields absolute current density values with a clear distinction of disjoint sources and sinks that allows us to follow each of these coordinated groups. Moreover, the measurement of the center of mass can be attained with high spatial precision, in the order of $\sim 10 \mu \mathrm{m}$. Our method paves the way for understanding how information is locally integrated and how ensembles of neurons within the hippocampal circuit may convey it.

\section{References}

Barnett L, Seth AK (2014) The MVGC multivariate Granger causality toolbox: a new approach to Granger-causal inference. J Neurosci Meth 223: 50-68. CrossRef Medline

Basu J, Zaremba JD, Cheung SK, Hitti FL, Zemelman BV, Losonczy A, Siegelbaum SA (2016) Gating of hippocampal activity, plasticity, and memory by entorhinal cortex long-range inhibition. Science 351:aaa5694. CrossRef

Bezanson J, Edelman A, Karpinski S, Shah VB (2017) Julia: a fresh approach to numerical computing. SIAM Rev 59:65-98. CrossRef

Bischofberger J, Engel D, Li L, Geiger JR, Jonas P (2006) Patch-clamp recording from mossy fiber terminals in hippocampal slices. Nat Protoc 1:2075-2081. CrossRef Medline

Boccara CN, Kjonigsen LJ, Hammer IM, Bjaalie JG, Leergaard TB, Witter MP (2015) Three-plane architectonic atlas of the rat hippocampal region. Hippocampus 25:838-857. CrossRef

Both M, Bähner F, von Bohlen und Halbach O, Draguhn A (2008) Propagation of specific network patterns through the mouse hippocampus. Hippocampus 18:899-908. CrossRef Medline

Bragin A, Engel JJr, Wilson CL, Fried I, Mathern GW (1999) Hippocampal and entorhinal cortex high-frequency oscillations $(100-500 \mathrm{~Hz})$ in human epileptic brain and in kainic acid-treated rats with chronic seizures. Epilepsia 40:127-137. CrossRef Medline

Buzsáki G (2015) Hippocampal sharp wave-ripple: a cognitive biomarker for episodic memory and planning. Hippocampus 25:1073-1188. CrossRef Medline

Buzsáki G (1986) Hippocampal sharp waves: their origin and significance. Brain Res 398:242-252. CrossRef Medline

Buzsáki G, Leung LS, Vanderwolf CH (1983) Cellular basis of hippocampal EEG in the behaving rat. Brain Res 6:139-171. CrossRef

Buzsáki G, Hsu M, Slamka C, Gage FH, Horváth Z (1991) Emergence and propagation of interictal spikes in the subcortically denervated hippocampus. Hippocampus 1:163-180. CrossRef Medline

Buzsáki G, Anastassiou CA, Koch C (2012) The origin of extracellular fields and currents-EEG, ECoG, LFP and spikes. Nat Rev Neurosci 13:407420. CrossRef Medline

de la Prida LM, Huberfeld G, Cohen I, Miles R (2006) Threshold behavior in the initiation of hippocampal population bursts. Neuron 49:131-142. CrossRef Medline

Dzhala VI, Staley KJ (2003) Transition from interictal to ictal activity in limbic networks in vitro. J Neurosci 23:7873-7880. CrossRef Medline

Ferrea E, Maccione A, Medrihan L, Nieus T, Ghezzi D, Baldelli P, Benfenati F, Berdondini L (2012) Large-scale, high-resolution electrophysiological imaging of field potentials in brain slices with microelectronic multielectrode arrays. Front Neural Circuits 6:80. CrossRef Medline

Foffani G, Uzcategui YG, Gal B, Menendez de la Prida L (2007) Reduced spike-timing reliability correlates with the emergence of fast ripples in the rat epileptic hippocampus. Neuron 55:930-941. CrossRef Medline

Franco LM, Beltrán JQ, Tapia JA, Ortiz F, Manjarrez E, Gutiérrez R (2016) Differential frequency-dependent antidromic resonance of the Schaffer collaterals and mossy fibers. Brain Struct Funct 221:1793-1807. CrossRef Medline

Gafurov B, Bausch SB (2013) GABAergic transmission facilitates ictogenesis and synchrony between CA3, hilus, and dentate gyrus in slices from epileptic rats. J Neurophysiol 110:441-455. CrossRef Medline

Gaillard R, Dehaene S, Adam C, Clémenceau, Hasboun D, Baulac M, Nac- cache L (2009) Converging intracranial markers of conscious access. PLoS Biology 7:e61. CrossRef Medline

Granger CWJ (1969) Investigating causal relations by econometric models and cross-spectral methods. Econometrica 37:424. CrossRef

Hájos N, Ellender TJ, Zemankovics R, Mann EO, Exley R, Cragg SJ, Freund TF, Paulsen O (2009) Maintaining network activity in submerged hippocampal slices: importance of oxygen supply. Eur J Neurosci 29:319 327. CrossRef Medline

Heinemann U, Beck H, Dreier JP, Ficker E, Stabel J, Zhang CL (1992) The dentate gyrus as a regulated gate for the propagation of epileptiform activity. Epilepsy Res Suppl 7:273-280. Medline

Henze DA, Urban NN, Barrionuevo G (1997) Origin of the apparent asynchronous activity of hippocampal mossy fibers. J Neurophysiol 78:24-30. CrossRef Medline

Herreras O (2016) Local field potentials: myths and misunderstandings. Front Neural Circuits 10:101. Medline

Jefferys JG, Menendez de la Prida L, Wendling F, Bragin A, Avoli M, Timofeev I, Lopes da Silva FH (2012) Mechanisms of physiological and epileptic HFO generation. Prog Neurobiol 98:250-264. CrossRef Medline

Kasyanov AM, Maximov VV, Byzov AL, Berretta N, Sokolov MV, Gasparini S, Cherubini E, Reymann KG, Voronink LL (2000) Differences in amplitude-voltage relations between minimal and composite mossy fibre responses of rat ca3 hippocampal neurons support the existence of intrasynaptic ephaptic feedback in large synapses. Neuroscience 101:323-336. Medline

Kneisler TB, Dingledine R (1995) Synaptic input from CA3 pyramidal cells to dentate basket cells in rat hippocampus. J Physiol 487:125-146. CrossRef Medline

Krook-Magnuson E, Armstrong C, Bui A, Lew S, Oijala M, Soltesz I (2015) In vivo evaluation of the dentate gate theory in epilepsy J Physiol 593:2379_ 2388. CrossRef Medline

Lindberg T (1990) Scale-space for discrete signals. IEEE Trans Pattern Anal Mach Intell 12:234-254. CrossRef

Manjarrez E, Vázquez M, Flores A (2007) Computing the center of mass for traveling alpha waves in the human brain. Brain Res 1145:239-247. CrossRef Medline

Morris G, Jiruska P, Jefferys JG, Powell AD (2016) A new approach of modified submerged patch clamp recording reveals interneuronal dynamics during epileptiform oscillations. Front Neurosci 10:519. Medline

Myers CE, Scharfman HE (2011) Pattern separation in the dentate gyrus: a role for the CA3 backprojection. Hippocampus 21:1190-1215. CrossRef Medline

Novak JL, Wheeler BC (1989) Two-dimensional current source density analysis of propagation delays for components of epileptiform bursts in rat hippocampal slices. Brain Res 497: 223-230 223. Medline

Ortiz F, Gutiérrez R (2015) Entorhinal cortex lesions result in adenosinesensitive high frequency oscillations in the hippocampus. Exp Neurol 271:319-328. CrossRef Medline

Paxinos G, Watson C (1997) The rat brain in stereotaxic coordinates. San Diego, CA: Academic Press.

Penttonen M, Kamondi A, Sik A, Acsády L, Buzsáki G (1997) Feed-forward and feed-back activation of the dentate gyrus in vivo during dentate spikes and sharp wave bursts. Hippocampus 7:437-450. Medline

Santhakumar V, Voipio J, Kaila K, Soltesz I (2003) Post-traumatic hyperexcitability is not caused by impaired buffering of extracellular potassium. J Neurosci 23:5865-5876. CrossRef Medline

Scharfman HE (1993) Activation of dentate hilar neurons by stimulation of the fimbria in rat hippocampal slices. Neurosci Lett 156:61-66. CrossRef Medline

Scharfman HE (1994) Synchronization of area CA3 hippocampal pyramidal cells and non-granule cells of the dentate gyrus in bicucullinetreated rat hippocampal slices. Neuroscience 59:245-257. CrossRef Medline

Scharfman HE (2016) The enigmatic mossy cell of the dentate gyrus. Nat Neurosci Rev 17:562-575. CrossRef

Schmidt-Hieber C, Jonas P, Bischofberger J (2008) Action potential initiation and propagation in hippocampal mossy fibre axons. J Physiol 586: 1849-1857. CrossRef Medline

Simon A, Traub RD, Vladimirov N, Jenkins A, Nicholson C, Whittaker RG, Schofield I, Clowry GJ, Cunningham MO, Whittington MA (2014) Gap junction networks can generate both ripple-like and fast ripple-like oscillations. Eur J Neurosci 39:46-60. CrossRef Medline 
Soltesz I, Losonczy A (2018) CA1 pyramidal cell diversity enabling parallel information processing in the hippocampus. Nat Neurosci 21:484-493. CrossRef Medline

Vincent L, Soille P (1991) Watersheds in digital spaces: an efficient algorithm based on immersion simulations. IEEE Trans Pattern Anal Mach Intell 13:583. CrossRef

Vivar C, Traub RD, Gutiérrez R (2012) Mixed electrical-chemical transmission between hippocampal mossy fibers and pyramidal cells. Eur J Neurosci 35:76-82. CrossRef Medline

Wenzel M, Hamm JP, Peterka DS, Yuste R (2017) Reliable and elastic propagation of cortical seizures in vivo. Cell Rep 19:2681-2693. CrossRef Medline

Wittner L, Miles R (2007) Factors defining a pacemaker region for synchrony in the hippocampus. J Physiol 584:867-883. CrossRef Medline

Xiong G, Metheny H, Johnson BN, Cohen AS (2017) Comparison of different slicing planes in preservation of major hippocampal pathway fibers in the mouse. Front Neuroanat 11:107. CrossRef Medline

Ylinen A, Bragin A, Nadasdy Z, Jando G, Szabo I, Sik A, Buzsáki G (1995) Sharp-wave-associated high-frequency oscillation $(200 \mathrm{~Hz})$ in the intact hippocampus: network and intracellular mechanisms. J Neurosci 14:3046. Medline

Zapfe WPK, Ortiz F, Gutiérrez R (2015) Computation of center of mass from voltage and current source density of epileptiform activity in the hippocampus. Paper presented at 69th Annual. Meeting of the American Epilepsy Society Philadelphia, December 4-8. 